\title{
DRAPE STUDY ON TEXTILES FOR CONCRETE APPLICATIONS
}

\author{
Vera Eckers, Steffen Janetzko, Thomas Gries
}

RWTH Aachen, Institut für Textiltechnik, Aachen, Germany, Otto-Blumenthal-Str. 1, 52074 Aachen, tel. +49 241 8024714, fax +49 241 8022422, vera.eckers@ita.rwth-aachen.de

\begin{abstract}
:
Textile reinforced concrete (TRC) is an eco-friendly material with a high freedom in design. As soon as complex curved parts are to be designed, the question of the drapability of the reinforcing materials arises. Different process parameters can be modified in the production of the reinforcing textiles which strongly influence the handling and the draping behaviour. To be able to choose a textile structure in the design stage which fulfils the requirements concerning drapability, a new test method was developed. This article describes this test method and shows results of a test series on different textile structures, including a brief discussion of the results. Finally, a transfer to a sample geometry is shown.
\end{abstract}

\section{Key words:}

Textile reinforced concrete, textile parameters, draping, test procedure.

\section{Introduction}

Textile reinforced concrete (TRC) is an eco-friendly material with a high freedom in design. Unlike steel reinforced concrete, the thickness of TRC is determined only by the load-bearing capacity as the used textiles are not corrosive. Therefore thicknesses of $1 \mathrm{~cm}$ are possible, which leads to a saving of concrete of up to $80 \%[4,7]$. Thus, building with TRC is climatefriendly because cement manufacturing is one of the highest $\mathrm{CO} 2$ sources worldwide. The possible savings are especially high as the building sector is the largest energy consumer (40 $\%)$ and $\mathrm{CO} 2$ emitter (36 \%) within the EU [5].

Textiles for TRC are open-meshed structures that consist of a $0^{\circ}$ - and a $90^{\circ}$-layer of reinforcement yarns made of alkaliresistant glass or carbon fibres. The yarns in the textile structure are straight to achieve good performance due to a low structural deformation. The open mesh is necessary to enable the concrete to penetrate the structure. The choice of a suitable reinforcement depends on the part geometry and the manufacturing process. These two aspects also affect the necessary textile tests. As soon as complex parts which are curved in more than one direction are to be designed, the question of the drapability of the reinforcing materials arises. Drapability is defined as the wrinkle-free application of planes on surfaces of a free dimensional geometry [1]. In the manufacturing process of textile reinforced materials, the reinforcing textile needs to be adjusted according to the flow of forces and therefore preferably to be wrinkle-free. Therefore the drapability is an important characteristic to check the feasibility of three-dimensionally formed parts on the one hand, and to analyse the load bearing-behaviour due to different fibre orientations on the other hand. The drapability depends on different characteristics. Among these are the bending stiffness, the shearing behaviour, the stress-strain behaviour and other characteristics such as thickness and the build-up sequence.

In the manufacturing process of the textile structures, different process parameters can be modified. Among these are the stitch length and the type of binding of the interlacing yarns. To test the influence of these parameters and to be able to predict the applicability of different textiles structures for various part geometries, a new test set-up was developed.

\section{Methodology}

Test set-up

In this test the textiles are positioned in a spherically curved bowl of a radius of either $300 \mathrm{~mm}$ or $1000 \mathrm{~mm}$. The $1000 \mathrm{~mm}$ radius form is the standard form; the $300 \mathrm{~mm}$ form is only used when no draping problems occur in the larger form. Even though most buildings have much larger radii, testing with the mentioned radii is suitable for two reasons: first, the test setup is not too large and second, more distinct differences can be found for the textile structures. This is useful for a classification of the textile structures. The procedure method of the draping test is shown in Figure 1.

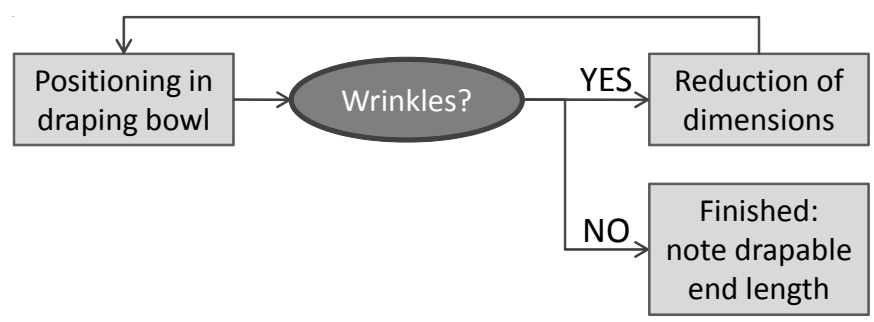

Figure 1. Procedure method of draping test.

Figure 2 visualises the test procedure in more detail.

The starting length of the textiles depends on the test form. This was set as $500 \times 500 \mathrm{~mm}$ for the form with $300 \mathrm{~mm}$ radius and $1200 \times 1200 \mathrm{~mm}$ for the form with $1000 \mathrm{~mm}$ radius. In the test the dimensions of the textiles are reduced in steps of $50 \mathrm{~mm}$ until draping without wrinkles becomes possible. Afterwards the edge lengths are measured. The drapability is the better the less the specimen needs to be reduced in size. In Figure 2 the small (left) and large (right) draping bowls are shown. In both cases textiles are placed in a way that causes wrinkles in the chosen dimensions. Therefore the edges need to be cut until a wrinkle-free alignment becomes possible. 

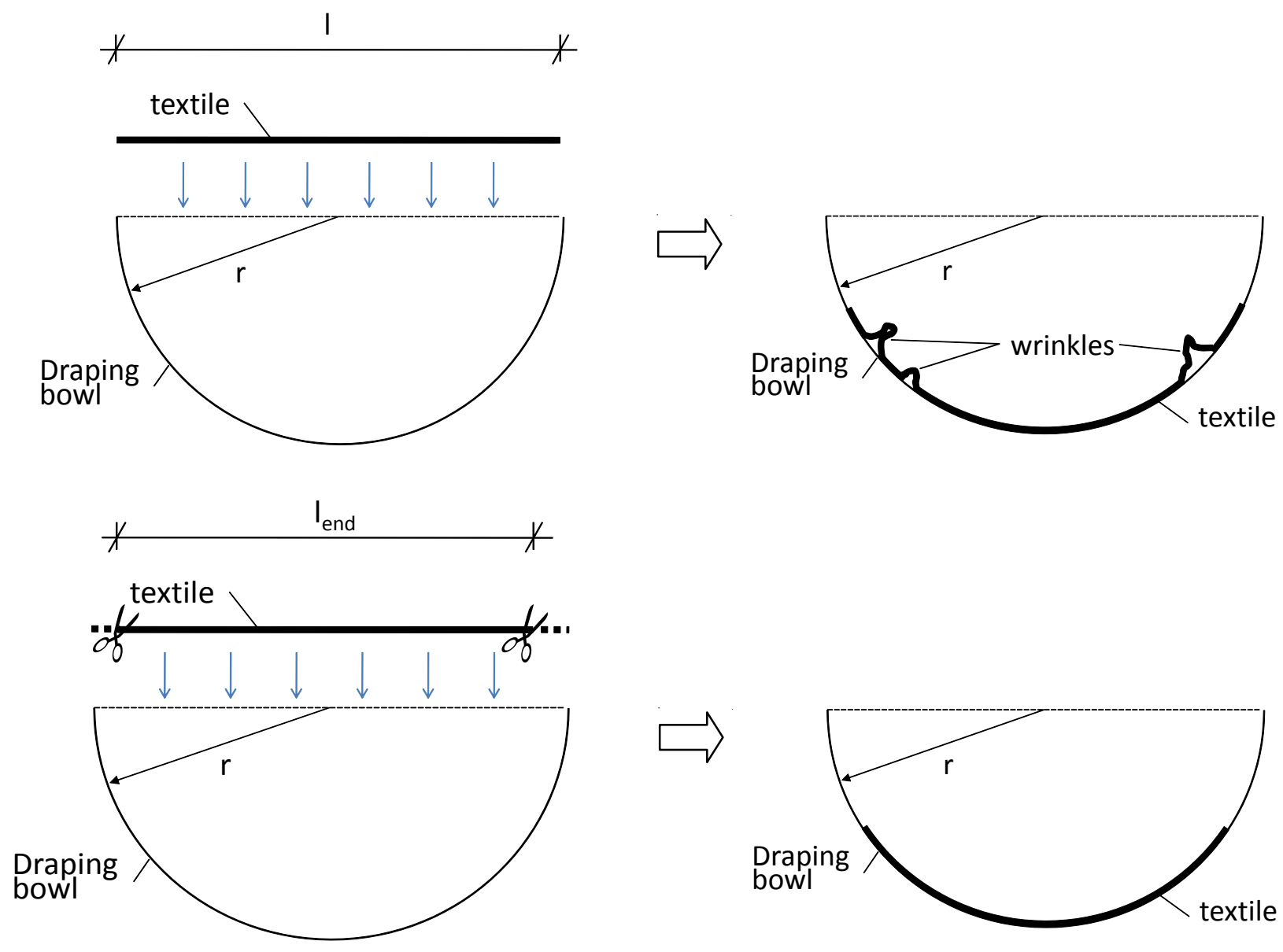

Figure 2. Test procedure of draping test.
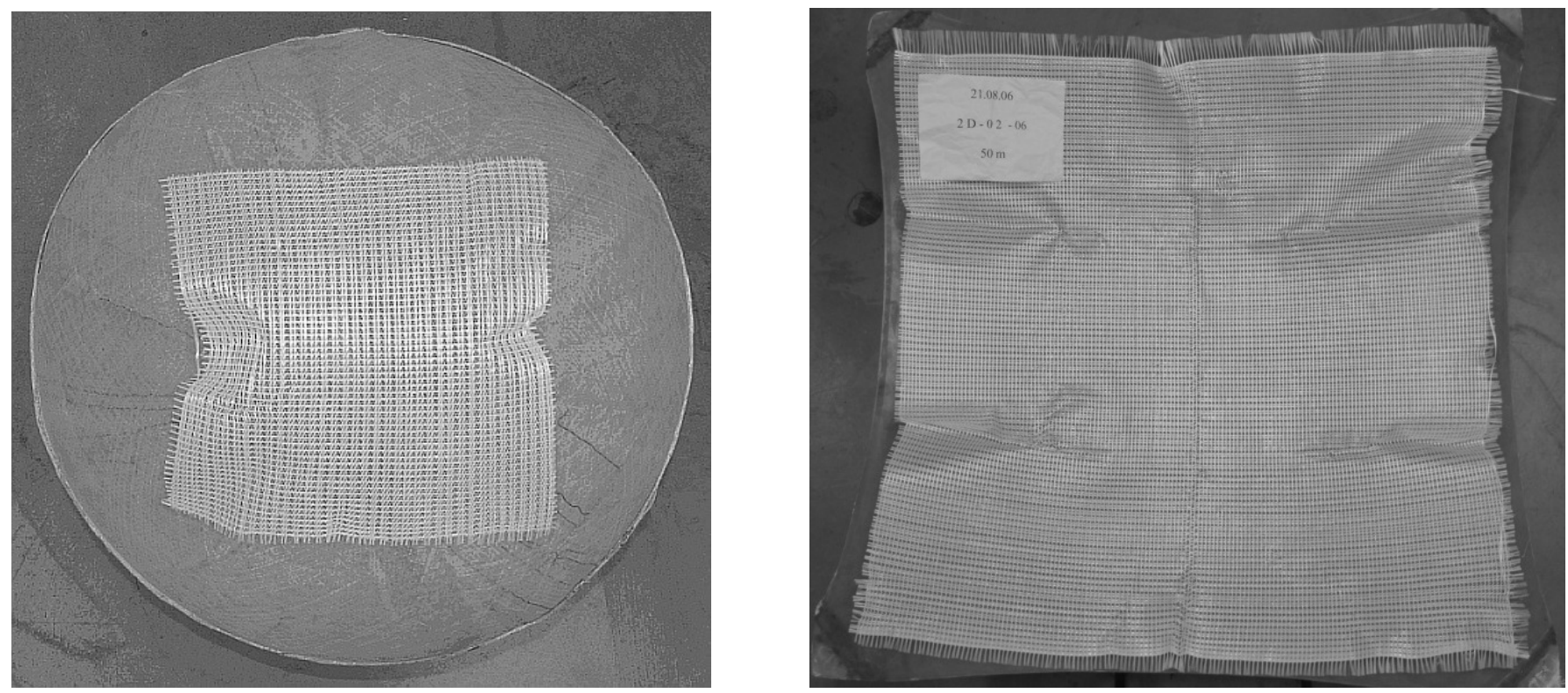

Figure 3. Small (left) and large (right) draping bowl, both with textile structures that cause wrinkles in the chosen dimensions and need to be shortened to achieve a wrinkle-free alignment.

\section{Prediction of applicability for various part geometries}

Draping problems mainly occur when the parts are curved in two directions. Therefore the draping bowl used for the tests is spherically curved. Depending on the drapable end length I and the radius $r$ of the draping bowl, the height $h$ can be calculated (Figure 3) [2].
This is done by first calculating the angle $\alpha$ depending on the drapable end length $/$ and the radius $r$.

$$
\begin{aligned}
& l=\pi \cdot r \cdot \frac{\alpha^{\circ}}{180^{\circ}} \\
& \alpha^{\circ}=\frac{180^{\circ}}{\pi} \cdot \frac{l}{r}
\end{aligned}
$$




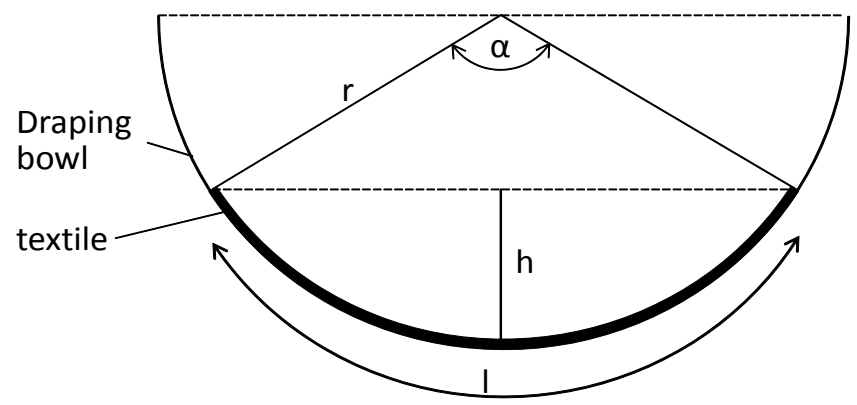

Figure 4. Draping bowl with drapable end length of textile $I$, radius $r$ and height $h$.

Having $\alpha$, the height $\mathrm{h}$ can be obtained in the following way:

$$
\begin{aligned}
& h=2 r \sin ^{2}\left(\frac{\alpha^{\circ}}{4}\right) \\
& h=2 r \sin ^{2}\left(\frac{45 l}{\pi r}\right)
\end{aligned}
$$

Having calculated $h$ the quotient $h / l$ can be generated. This quotient can also be generated for all kinds of part geometries independently from the type of curvature. This way it is possible to make a first choice of textile structure which fulfils the requirements concerning draping. To guarantee a wrinkle-free application, the quotient $h / l$ of the part needs to be smaller than or equal to the quotient $h / l$ of the chosen textile.

$$
\left(\frac{h}{l}\right)_{p a r t} \leq\left(\frac{h}{l}\right)_{k r i t}
$$

\section{Results and discussion \\ Tested material}

In concrete parts mainly non-crimp fabrics (NCFs) with rovings in $0^{\circ}$ - and $90^{\circ}$-direction are used. The material used is mainly AR-glass due to the lower price in comparison to carbon. The rovings are integrated in the mesh system as straight yarns. The mesh system is only responsible for maintaining the positions of the rovings during further processing. But the mesh system strongly influences the geometry of the roving and the mechanical behaviour. Therefore textiles with different types of lacing and different stitch lengths are investigated concerning their draping behaviour [3].

Two types of lacing were investigated: plain stitch and tricot stitch and a combination of the two. In addition two different finenesses of the rovings (1200 tex and 2400 tex) and three different stitch lengths $(2.1 \mathrm{~mm}, 2.4 \mathrm{~mm}$ and $6.3 \mathrm{~mm})$ were considered. Images of the different types of lacing are shown in Figure 4.

The textiles were investigated in the small draping bowl as a wrinkle-free alignment could be achieved for some of the textiles in the large draping bowl right from the beginning.

\section{Test results and discussion}

The test results are shown in Figure 5 . It can be clearly seen that the textile with the plain stitch has the longest drapable end length with approx. $500 \mathrm{~mm}$. There is no significant difference with the different stitch lengths. For the tricot stitch, two different finenesses were investigated (1200 tex and 2400 tex). For the stitch length of $2.1 \mathrm{~mm}$ the drapable end length is the same for the different finenesses, with approx. $300 \mathrm{~mm}$. For increasing stitch lengths, the drapable end length increases for both finenesses ending at approx. $400 \mathrm{~mm}$ for the textile with 1200 tex and approx. $350 \mathrm{~mm}$ for the textile with 2400 tex.

Plain stitch

Figure 5. Textiles investigated. 


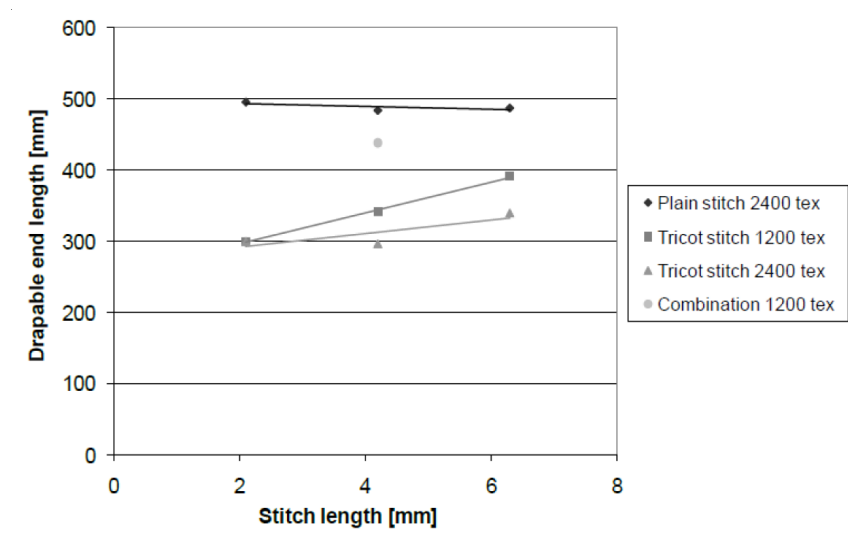

Figure 6. Test results of non-crimp fabrics with different types of lacing and different stitch lengths.

The following equations can be created when considering a linear coherence.

$$
\text { Drapable end length }{ }_{2400 t e x, \text { Tricot }}=9.5 x+272.2
$$

The equations are valid for a stitch length in the investigated field of 2.1 to $6.3 \mathrm{~mm}$. An extrapolation to smaller or longer stitch lengths is likely for small aberrations. For the combination of the two types of lacing, only one textile structure with 1200 tex glass rovings and a stitch length of $4.2 \mathrm{~mm}$ was tested. With a drapable end length of $450 \mathrm{~mm}$, it can be positioned between the two types of lacing, plain stitch and tricot stitch. The following aspects can be summarized:

- The continuous mesh system of the tricot stitch prevents large yarn movement.

- For the tricot stitch, the higher stitch length leads to a less tight mesh system. This allows more yarn movement and increased shearability, resulting in greater drapable end lengths.

- For the plain stitch, the yarns have a greater sliding ability independent from the stitch length.

- Different finenesses only have a small effect.

Using the equations described above, the relation $h / l$ of the height $h$ of the textiles in the draping bowl and the drapable end length / can be generated. For the investigated textiles this relation is shown in Table 1.

Table 1. Relation $h / l$ of the investigated textiles.

\begin{tabular}{|l|c|c|c|}
\hline \multirow{2}{*}{\multicolumn{1}{|c|}{ Textile }} & \multicolumn{3}{|c|}{ Stitch length } \\
\cline { 2 - 4 } & $\mathbf{2 . 1} \mathbf{~} \mathbf{4 m}$ & $\mathbf{4 . 2} \mathbf{~} \mathbf{m}$ & $\mathbf{6 . 3} \mathbf{~ m m}$ \\
\hline 1200 tex Tricot stitch & 0.122 & 0.138 & 0.158 \\
\hline 1200 tex Combination & & 0.175 & \\
\hline 2400 tex Tricot stitch & 0.122 & 0.121 & 0.138 \\
\hline 2400 tex Plain stitch & 0.195 & 0.191 & 0.192 \\
\hline
\end{tabular}

These relations can be used for a first choice of textiles in the design stage of textile reinforced concrete parts, taking into account the aspect of drapability. This is shown in the following.

\section{Transfer to example part}

Within the Collaborative Research Center 532: Textile Reinforced Concrete - Development of a new technology project a large demonstrator is being built with a two-dimensionally curved roof. An image of this demonstrator is shown in Figure
7. The demonstrator consists of four basic modules with dimensions of $7 \times 7 \mathrm{~m}$. The lowest point is $0.865 \mathrm{~m}$ below the highest point, leading to a relation $h / l$ of 0.124 .
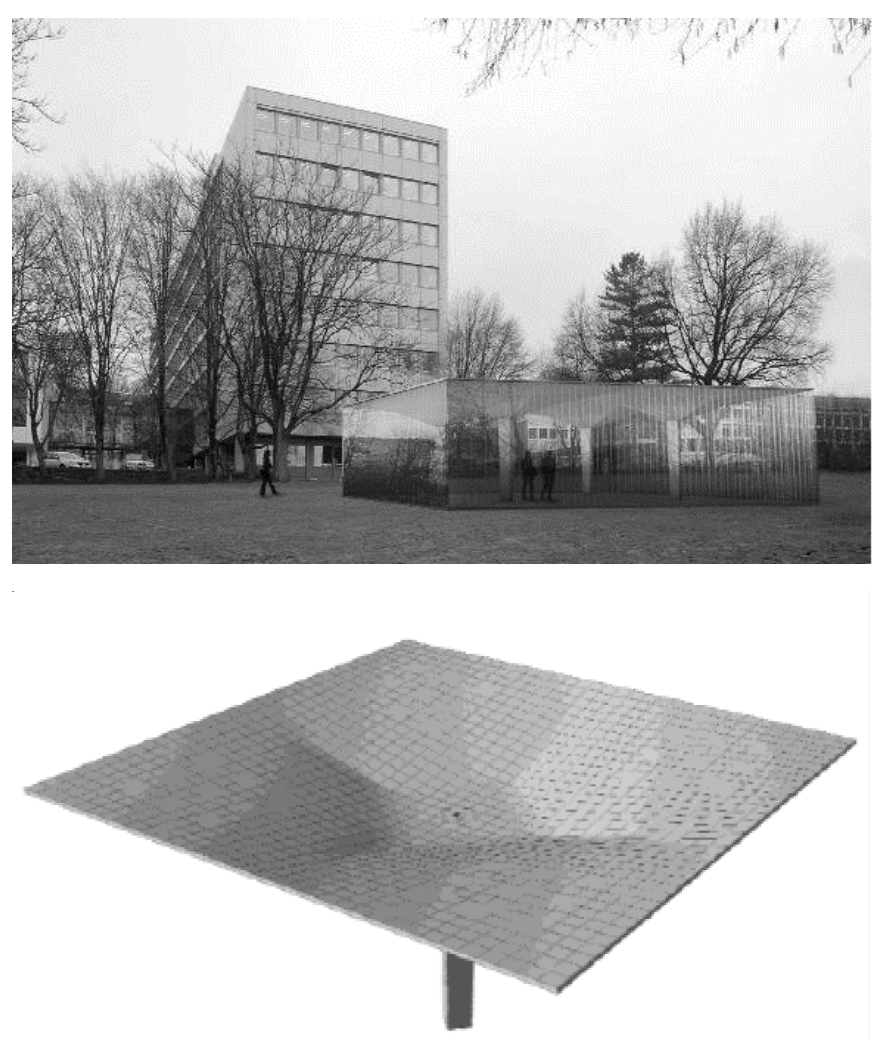

Figure 7. Demonstrator of Collaborative Research Center 532: Information pavilion located next to the building of the faculty of civil engineering (up), basic module (down) [6].

In cross-sections parallel to the edges, the cross-sectional profile consists of two straight lines meeting in the middle of the structure (Figure 8, Section A). This leads to a curved crosssectional profile in the diagonal direction (Figure 8 , Sections $B$ and $\mathrm{C})$.

At first, it was planned to take a textile structure with AR-glass 1200 tex in tricot stitch with a stitch length of $4.2 \mathrm{~mm}$. For this structure a wrinkle-free positioning can be guaranteed for the existing relation $\mathrm{h} / \mathrm{l}$.

$$
\left[\left(\frac{h}{l}\right)_{\text {demonstrator }}=0.124\right] \leq\left[\left(\frac{h}{l}\right)_{\text {krit,textile }}=0.138\right]
$$

Due to the high degree of reinforcement in the edges and with the very thin $6 \mathrm{~cm}$ part thickness in this area, it was not possible to include the necessary number of reinforcement layers in preliminary tests. Therefore it was decided to take a carbon yarn with 800 tex and the same textile configurations instead, leading to a reduction of the number of layers from 16 to 12 . The drapability of this structure can be assumed as sufficient, as the textile parameters were not varied.

\section{Conclusions}

The developed test method described in this article enables the designer of complex curved TRC parts to make a first choice of the reinforcing textiles, taking the aspect of drapability into account. The tests performed on textile structures with different process parameters have shown that the drapability of textiles with a plain stitch is much greater than with a tricot stitch. For 


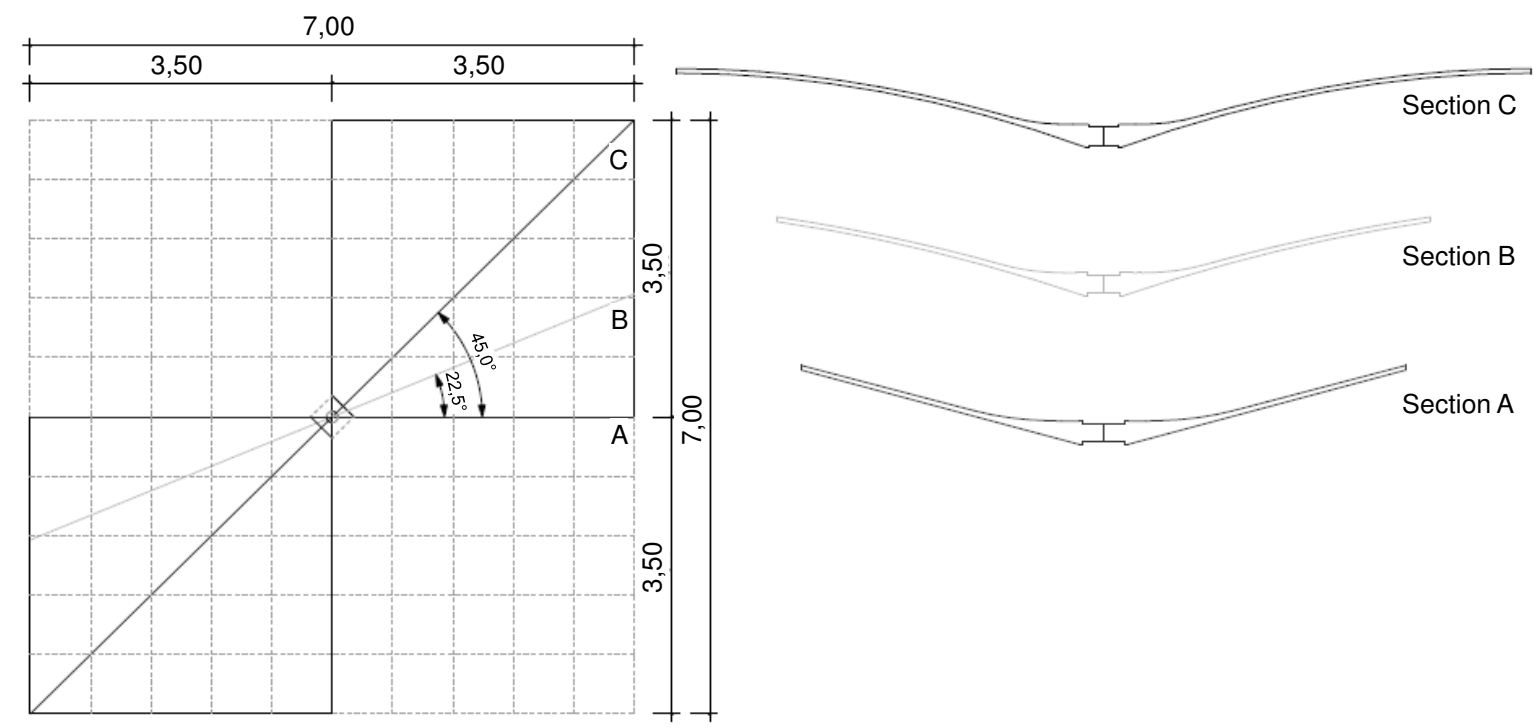

Figure 8. Cross-sectional profiles of the demonstrator [6].

textiles with tricot stitch, the drapability increases with increasing stitch length. For the plain stitch, no such influence can be measured. The changeover to different finenesses has no major effect.

\section{Acknowledgement}

The work reported in this article was partly funded within the Collaborative Research Centre 532 by the German Research Foundation (DFG) at RWTH Aachen University. The authors are grateful for the financial support.

\section{References:}

1. Denninger, F. (Hrsg.): Lexikon Technische Textilien. Frankfurt a. Main: Dt. Fachverlag, 2009.

2. Eckers, V.: Multiskalenanalyse gitterartiger Textilstrukturen für textilbewehrten Beton. Aachen, Techn. Hochsch., Diss., 2011; Zugl. Aachen: Shaker, 2011.

3. Gries, T.; Janetzko, S.; Kravaev, P.: Textile Verstärkungsstrukturen: Übersicht der Forschungsaktivitäten im Rahmen des SFB 532. In: Curbach, Manfred; Ortlepp, Regine (Hrsg.): Textilbeton in Theorie und Praxis: Tagungsband zum 6. Kolloquium zu textilbewehrten Tragwerken (CTRS6); Gemeinsames Abschlusskolloquium der Sonderforschungsbereiche 528 (Dresden) und 532 (Aachen), Berlin, 19.9.2011 - 20.9.2011 - Dresden: Technische Universität, 2011, S. 15-26.

4. Janetzko, S.; Tomoscheit, S.: Project Life Insu-Shell: reducing the carbon footprint in concrete constructions. European Conference on Sustainable Building: Towards 0-Impact Building and Environment, Maastricht, HeusdenZolder, Aachen, Li?ge, 11, 12 \& 13 October 2010.

5. NN: Position zur Neufassung der EU-Richtlinie über die Gesamtenergieeffizienz von Gebäuden. Deutsche Umwelthilfe, Juni 2009, http://www.eu-koordination.de/PDF/ Position_\%20EU-Gebaeuderichtlinie_2009, 02.06.2010.

6. Schätzke, C.; Schneider, H. N.; Joachim, T.; Feldmann, M.; Pak. D.; Geßler, A.; Hegger, J.; Scholzen, A.: Doppelt gekrümmte Schalen und Gitterschalen aus Textilbeton. In: Curbach, Manfred; Ortlepp, Regine (Hrsg.): Textilbeton in Theorie und Praxis: Tagungsband zum 6. Kolloquium zu textilbewehrten Tragwerken (CTRS6) ; Gemeinsames
Abschlusskolloquium der Sonderforschungsbereiche 528 (Dresden) und 532 (Aachen), Berlin, 19.9.2011 - 20.9.2011 - Dresden : Technische Universität, 2011, S. 15-26.

7. Tomoscheit, S.; Janetzko, S.; Gries, T.: Per Spatenstich ins Erdreich zu neuen Horizonten im Gebäudebau: ökologisch verträglicher Fassadenbau mit Sandwichelementen aus textilbewehrtem Beton (The first clump of earth breaks new ground in building construction: construction of eco-friendly facades using sandwich elements made from textile-reinforced concrete). Kettenwirk-Praxis 42 (2008), H. 1, S. 30-31. 